\title{
QUEEN'S
UNIVERSITY
BELFAST
}

\section{Social support mediates the relationships between extraversion, neuroticism, and cognitive function in older adults}

McHugh Power, J. E., Lawlor, B. A., \& Kee, F. (2017). Social support mediates the relationships between extraversion, neuroticism, and cognitive function in older adults. Public Health, 147, 144-152.

https://doi.org/10.1016/j.puhe.2017.02.015

\section{Published in:}

Public Health

\section{Document Version:}

Peer reviewed version

Queen's University Belfast - Research Portal:

Link to publication record in Queen's University Belfast Research Portal

\section{Publisher rights}

Copyright $\odot 2017$ Published by Elsevier Ltd on behalf of The Royal Society for Public Health. All rights reserved.

This manuscript version is made available under the CC-BY-NC-ND 4.0 license http://creativecommons.org/licenses/by-nc-nd/4.0/,which permits distribution and reproduction for noncommercial purposes, provided the author and source are cited

\section{General rights}

Copyright for the publications made accessible via the Queen's University Belfast Research Portal is retained by the author(s) and / or other copyright owners and it is a condition of accessing these publications that users recognise and abide by the legal requirements associated with these rights.

Take down policy

The Research Portal is Queen's institutional repository that provides access to Queen's research output. Every effort has been made to ensure that content in the Research Portal does not infringe any person's rights, or applicable UK laws. If you discover content in the Research Portal that you believe breaches copyright or violates any law, please contact openaccess@qub.ac.uk. 


\title{
Social Support Mediates the Relationships between Extraversion, Neuroticism, and Cognitive Function in Older Adults
}

\author{
Dr Joanna Edel McHugh Powera,b, Professor Brian A Lawlor ${ }^{\mathrm{b}}$, Professor Frank Kee ${ }^{\mathrm{a}}$ \\ a: UK CRC Centre of Excellence for Public Health, Institute of Clinical Sciences \\ Block B, Grosvenor Road, Queen's University Belfast, Royal Victoria Hospital, \\ Belfast BT12 6BJ. \\ b: Institute of Neuroscience, Lloyd Institute, Trinity College, Dublin 2, Ireland.
}

Corresponding Author: Dr McHugh Power: mchughje@tcd.ie

Abstract

Objectives: We supplement existing findings on a link between social support and cognitive function in later life by considering the role of personality as an antecedent to both, and of social support as a mediator of the link between personality and cognitive function.

Study Design: An observational cohort study.

Methods: We evaluated social support using the Lubben Social Network Scale, across 624 adults aged over 60, and investigated this measure as a mediator of the relationships between Extraversion and Neuroticism at baseline 2007-2009, and cognitive function at follow-up, 2 years later. A half-longitudinal mediation design, within a Structural Equation Modelling framework, was used.

Results: There was a direct effect of Extraversion, such that lower levels were related to higher scores of cognitive function. There was no significant direct effect of Neuroticism on cognitive function at follow-up. Social support partially mediated the paths between both Extraversion and Neuroticism, and cognitive function at followup. Decomposing the mediation effects by using social support subscales (measuring support from Friends, Relatives, and Neighbours) showed meaningful indirect effects for both predictors.

Conclusion: Results suggest that social support may offer a target for interventions for cognitively at-risk older adults, and add to the existing empirical evidence describing the link between personality and cognitive function.

Keywords: cognitive assessment, social support, ageing, personality 
Introduction

Ageing can often be accompanied by cognitive ageing, a process of progressive but non-pathological changes in functions such as memory. The most commonly-cited risk factors for cognitive ageing include: smoking ${ }^{1}$, metabolic syndrome ${ }^{2}$ physical inactivity ${ }^{3}$, depression ${ }^{4}$, and low educational attainment ${ }^{5}$. Latterly social factors such as socioeconomic status ${ }^{6}$, marital status ${ }^{7}$, social network size ${ }^{8}$, social isolation ${ }^{9}$, and social integration ${ }^{10}$ have also been implicated.

Personality traits have been suggested as a factor in the etiology of both social support and cognitive functioning. Among the most commonly assessed personality traits are Extraversion and Neuroticism ${ }^{11,1}$. Extraversion is defined by Eysenck as describing an individual's basal cortical arousal, with low levels indicating an Extravert personality, while high levels indicate an Introvert personality ${ }^{11}$. Low levels of basal cortical arousal purportedly cause the individual to seek stimulation in the form of sociability, risk-taking, and surgence, and as such, Extraversion is by definition associated with social support ${ }^{13}$.

Extraversion may be related to cognitive function because it engenders sensitivity to external reward, which may promote diligence ${ }^{14}$. Extraversion is also associated with increased levels of positive affect, which can enhance aspects of cognitive function ${ }^{15}$. Findings are extremely mixed when it comes to the directionality of the association between Extraversion and cognitive function. While high levels of Extraversion have been found to relate to lower likelihood of cognitive decline at 25-year follow-up ${ }^{16}$, lower levels of Extraversion were elsewhere found to be related to desirable outcomes in cognitive functioning over time ${ }^{17}$. Yet other researchers have shown no association ${ }^{18,19}$. The inconsistency of findings linking Extraversion and cognitive outcomes was remarked upon in a recent review of the literature ${ }^{20}$.

\footnotetext{
${ }^{1}$ While the competing five factor model (inclusive of openness to experience, agreeableness, and conscientiousness) has also been explored in cognitive functioning literature (12. Costa PT, Fozard JL, McCrae RR, Bossé R. Relations of Age and Personality Dimensions to Cognitive Ability Factors. Journal of gerontology. 1976; 31:663-9.), we limit our discussion for reasons of parsimony to the former two traits of Neuroticism and Extraversion. Our data collection took place within a larger cohort study for which it was seen as more prudent to focus our efforts on two traits measured using a large number of items, although we acknowledge that an alternative solution would have been to use a shorter scale measuring all five traits.
} 
Understanding the nature of mediators may help to elucidate the nature of the association between Extraversion and cognitive functioning. One such potential mediator is social support. Individuals with high levels of Extraversion are more likely to seek social support ${ }^{21}$, and as has been demonstrated above, higher levels of social support are associated with better cognitive functioning. As such, with this potential mediator in mind, it would make sense to expect a positive association between Extraversion and cognitive functioning.

Neuroticism is defined by Eysenck as an individual's proneness to psychological distress, caused by the stability of one's cortical arousal ${ }^{11}$ such that instability in this system is associated with high levels of Neuroticism. This instability leads to anxiety, distress, irrationality, and emotional lability. Neuroticism is associated with social support, in that high levels of Neuroticism are related to lower levels of social support ${ }^{21-23}$.

The theoretical underpinnings of a link between Neuroticism and cognitive function have also been considered at length. High levels of Neuroticism may involve intrusive, worrisome thoughts, which may reduce resources available for performance in cognitive testing ${ }^{24}$. High levels of Neuroticism may also impact cognitive function via their association with HPA-axis dysfunction ${ }^{25,26}$. In comparison with Extraversion, the literature on the link between Neuroticism and cognitive function is quite consistent and points towards a deleterious impact of high levels of Neuroticism on cognitive function in later life ${ }^{17,20,27,28}$ (but see $^{29}$ ).

Given the contested nature of the association between personality and cognitive function, calls have been made by Austin and colleagues to more closely explore potential mediators of the link between personality and cognitive function ${ }^{30}$. Our aim was to address the absence of individual level factors in recent analyses relating to social support and health outcomes ${ }^{31}$ while also responding to Austin's call, by examining social support as a mediator of the association between personality traits (Extraversion and Neuroticism) and overall cognitive function in older adults over time. Additionally, it is expected that furthering the understanding of social support as a mediator in the relationship between Extraversion and 
cognitive function will elucidate the hitherto contradictory findings on the direction of this relationship ${ }^{2}$.

The scale used to evaluate social support measures support from friends, relatives, and neighbours separately. As such, we appended additional analyses investigating whether scores on these separate subscales mediate the relationships between Extraversion/Neuroticism and cognitive outcomes (see Supplementary Materials), since the source of social support has previously been shown to have different effects on health outcomes ${ }^{32}$.

Hypotheses

Hypothesis 1: Social support will mediate the positive relationship between Extraversion and a global measure of cognitive function.

Hypothesis 2: Social support will mediate the negative relationship between Neuroticism and a global measure of cognitive function. Hypothesis 3: Different sources of social support (from friends, relatives, and neighbours) may have different mediating effects on the relationships explored in Hypotheses 1 \& 2.

\section{Methods}

Participants and design

A convenience sample of 624 community-dwelling adults aged over 60 was initially recruited to a biopsychosocial geriatric assessment at the (information removed for review), constituting a longitudinal observational cohort study,

2 Our planned analysis has three potential outcomes:

1. Positive association between Extraversion and cognitive functioning, consistent (positive) mediation effect of social support. This will be in accordance with previous findings.

2. Positive or negative association between Extraversion and cognitive functioning, no mediation effect. This wil contribute (but not necessarily improve upon) to evidence from previous findings.

3. Inconsistent Mediation Effect (i.e. the sign of the mediation effect opposite that of the direct effect). This would look like one of two things: either Extraversion positively predicts cognitive functioning but negatively predicts social support (just because the individual wants higher levels does not mean that they receive them; alternatively, individuals high in Extraversion may have higher standards for social support and so rate their actual levels as lower), or Extraversion negatively predicts cognitive functioning but positive predicts social support (so social support ameliorates the negative impact of extraversion on cognitive functioning). 
between 2007 and 2009. The sample is described elsewhere (information removed for review), and fit the criteria of being medically stable (i.e. no acute infection, stroke, or myocardial infarction), able to walk independently and attend the hospital for assessment, and able to provide informed consent. Ethical approval was obtained from the Institutional Ethics Committee, and the work was performed in accordance with the Declaration of Helsinki. The majority (66.8\%) of all participants were self-referrals, having seen advertisements for the research in national media. The rest of the participants (33.2\%) were referred from health professionals. Attempts were made to contact all 624 original participants; 30 had died and 37 were not contactable. Of the remaining 557 participants, 510 were contacted and agreed to participate in a telephone screen. Of these 510,447 agreed to participate in a clinic- or home-based follow-up assessment two years later (2009-2011; see Table 1 for participant characteristics). The global attrition weight between waves was $26 \%$. As such the sample size for the analyses currently reported is 447 . The protocol of the follow-up assessment was shorter than the baseline assessment due to time and resource constraints. All participants gave informed written consent to take part.

*Table 1 about here*

\section{Measures}

A broad range of health, psychosocial, cognitive, demographic and behavioural information was collected during the assessment. Here we focus on the measures relevant to the current analysis.

Demographic information (age, gender, education) was gathered for all participants at time 1. Personality was assessed at time 1 using the Extraversion and Neuroticism subscales of the Eysenck Personality Questionnaire (revised version; $\left.E P Q-R^{; 3}\right)$. Each subscale uses 24 items to assess a personality trait. Both scales were previously found to be reliable and valid ${ }^{34}$. In our dataset, internal reliability was found to be of acceptable levels (Cronbach's alpha was 0.715 for Extraversion and 0.742 for Neuroticism). 
Social support was measured at baseline and follow-up using the Lubben Social Network Scale (LSNS; ${ }^{35}$, an 18 -item scale assessing the availability of social support to the individual from friends, relatives and neighbours. The scale includes items such as "How many family members do you see or hear from at least once a month?" and "How often do you hear from the neighbour with whom you have the most contact?" The scale demonstrates good psychometric properties (Cronbach's alpha $=0.82 ;$ Lubben \& Gironda, 2004) and internal reliability in the current cohort was high (Cronbach's alpha $=0.831$ ).

Global cognitive function was measured at baseline and follow-up using the Mini-mental State Examination ${ }^{36}$, an 11 -item scale focused on assessing cognitive status and screening for dementia in older adults. Questions on the MMSE assess attention, orientation, memory, naming, following verbal and written commands, sentence construction, and constructional praxis. Maximum score on the MMSE is 30 , and in the (information removed for review) population a score of 23 or below indicates a likelihood of cognitive impairment (information removed for review) ${ }^{37}$. The MMSE has consistently been shown to have good reliability and validity ${ }^{38}$. The MMSE was administered and scored by clinical research nurses and research psychologists (with a minimum education level of M.A./MSc in Psychology) who were trained and supervised by a senior clinical neuropsychologist.

\section{Data analysis}

We used structural equation modelling to describe a mediation model, within the lavaan package in $\mathrm{R}$ software ${ }^{39}$. This package allows researchers to specify paths and measurement models, and use path labels to specify mediation effects. While longitudinal data are required for a mediation model to be specified, some researchers ${ }^{40}$ argue for the validity of the "half-longitudinal" design. In this design, data across two waves can be used to evaluate mediation. Cole and Maxwell argue that a two-wave model is limited in the mediation analyses it can cater for, since typically either $\mathrm{X}$ and $\mathrm{M}$ are measured contemporaneously, or $\mathrm{M}$ and $\mathrm{Y}$ are measured contemporaneously, leading to bias in coefficients of $\mathrm{X}$ on $\mathrm{M}$, or $\mathrm{M}$ on $\mathrm{Y}$. However, Cole and Maxwell recommend that in order to work with two waves of data, M and $\mathrm{Y}$ must be measured at both time points. They recommend estimating path a as the regression of the mediator at time 2 on $\mathrm{X}$, controlling for the mediator at time 1 . 
Path $b$ then is estimated as regression of $Y$ at time 2 on the mediator at time 1 controlling for $\mathrm{Y}$ at time 1. Given an assumption of stationarity (that path $\mathrm{b}$ between mediator at time 1 and $\mathrm{Y}$ at time 2 is equal to the path $\mathrm{b}$ between mediator at time 2 and $\mathrm{Y}$ at time 3 ), the product of paths $\mathrm{a}$ and $\mathrm{b}$ represents an estimate of the mediation effect of $\mathrm{X}$ on $\mathrm{Y}$ through $\mathrm{M}$. This design allows one to estimate partial mediation only.

Indirect effects constitute a product of coefficients, and as such calculating effect sizes is accomplished by squaring the typical Cohen's values of .1, .3, and .5 for small, medium and large effect sizes, giving guidelines of $.01, .09$, and .25 respectively (see davidakenny.net/cm/mediate.htm). Additionally, for each model (see Tables 3-4, Supplementary Materials) bootstrapped 95 per cent confidence intervals were calculated for the unstandardised estimates.

\section{Results}

Participant characteristics are described in Table 1 and a correlation matrix is presented in Table 2. In this table, correlations are significant between MMSE (time 1), and: MMSE (time t2; positive), and LSNS (times 1 and 2; positive). MMSE (time 2) is related to: Extraversion (negative) and LSNS (times 1 and 2; positive). Neuroticism is associated with: Extraversion and LSNS (times 1 and 2)(all negative but did not survive Bonferroni corrections). Extraversion is associated with: MMSE (time 2 but not time 1; negative), and LSNS (times 1 and 2; positive).

Extraversion and Cognitive Function

A structural equation model (Model 1) was created, with age, gender, and education level as covariates. A full-information maximum likelihood estimator was used to impute missing data. Path a constituted a regression of LSNS scores at time 2 on Extraversion at time 1, controlling for LSNS scores at time 1. Path b constituted the regression of MMSE at time 2 on LSNS scores at time 1, controlling for MMSE scores at time 1. Mediation and total effects (inclusive of the direct effects of Extraversion on MMSE at time 2) were specified.

Some fit indices indicated that the model was a good fit [Comparative Fit Index $(\mathrm{CFI})=0.933$, Standardised Root Mean Square Residuals $=0.04 ; \chi 213=482.5$, $p<0.001$, Tucker Lewis Index $(T L I)=0.78$, root mean square error of approximation (RMSEA) $\left[0.13\left(\mathrm{Cl}_{95}=0.09-0.18\right)\right]$. Significant mediating $(\beta=0.32, \mathrm{p}<0.001$; large 
effect size) and total ( $\beta=0.19, p<0.001$; See Table 3; See Figure 1 ) effects were found. The direct negative effect suggested that low levels of Extraversion were related to highest levels of cognitive function $(\beta=-0.11, p<0.01)$, and since the relationships between LSNS scores and both Extraversion $(\beta=0.07, p=0.07)$ and cognitive function $(\beta=0.5, p<0.001$ ) were positive, the mediation effect is inconsistent in nature: while Extraversion exerts a negative effect on cognitive function, social support mediates such that it exerts a positive effect, and the magnitude of the indirect effect flips the total effect into an overall positive effect between Extraversion and cognitive functioning.

Since the sample was a convenience sample, and no a priori sample size calculation was conducted, a post hoc power calculation was performed. In structural equation models, the RMSEA figure can be used to calculate power. We followed guidelines ${ }^{41}$ in measuring not-close fit (since our RMSEA confidence intervals were above 0.05), and evaluated power using the null RMSEA and alternative RMSEA figures derived from the above model. Using these guidelines power was 0.99 , implying that there was a $99 \%$ probability of rejecting the null hypothesis if it was false (i.e. the probability of not making a Type II error).

*Table 3 about here*

*Figure 1 about here*

A supplementary analysis, with the three subscales of the LSNS scale as mediators, (but otherwise identical to Model 1) was performed. This model was a good fit $\left[\mathrm{CFI}=0.95, \mathrm{TLI}=0.88, \mathrm{RMSEA}=0.08\left(\mathrm{Cl}_{95}=0.06-0.09\right), \mathrm{SRMR}=0.05, \chi 2{ }_{38}=\right.$ 862.4, $p<0.001]$, and indirect effects were significant for all three subscales: Friends $\beta=0.28, p<0.001 ;$ large effect size $)$, Relatives $(\beta=0.26, p<0.001 ;$ large effect size $)$ and Neighbours $\beta=0.28, p<0.001$; large effect size). (see Supplementary Materials). Inspecting the paths within these models indicated that mediation effects were likely to be small in magnitude, in contrast to the effect sizes found in the mediation effects (mediation effects can be misleading in half-longitudinal models and must be interpreted with caution).

\section{Neuroticism and Cognitive Function}


A second model, identical to Model 1, was created with Neuroticism as the exogenous variable. Mediation effects and total effects (inclusive of the direct effects of Neuroticism on MMSE at time 2) were specified.

Some fit indices indicated that the model was a good fit [CFI=0.942, SRMR = $\left.0.04 ; \chi 2_{13}=470.9, \mathrm{p}<0.001 ; \mathrm{TLI}=0.81, \mathrm{RMSEA}=0.12\left(\mathrm{Cl}_{95}=0.08-0.16\right)\right]$. Significant mediating ( $\beta=0.23, p<0.01$; large effect size) and total $(\beta=0.25, p<0.01$; See Table 4; See Figure 2) effects were observed. No significant direct effect was observed between Neuroticism and cognitive function $(\beta=0.02, p>0.05)$, although the total and mediating effects were positive (see above). Neuroticism had a (trending) negative association with social support $(\beta=-0.07, p=0.06)$ while social support had a positive association with cognitive function $(\beta=0.103, p<0.025)$. This implies that while Neuroticism did not have an effect directly on cognitive function, it did exert a small effect via its negative association with cognitive function, and the association between social support and cognitive function was sufficient to lead to a total positive effect overall. For this model, using the same guidelines above, power was calculated to be 0.99 , implying that there was a $99 \%$ probability of rejecting the null hypothesis if it was false.

*Table 4 about here*

Supplementary analyses evaluating the subscales of the LSNS as mediators of the relationship between Neuroticism and cognitive function were also conducted (see Supplementary Materials). This model was a good fit [CFI $=0.95, T L I$ $\left.=0.89, \mathrm{RMSEA}=0.07\left(\mathrm{Cl}_{95}=0.05-0.09\right), \mathrm{SRMR}=0.047, \chi 2{ }_{38}=846.4, \mathrm{p}<0.001\right]$.

Significant mediating effects were observed for social support from Friends ( $\beta$ $=0.21, p<0.001 ;$ moderate effect size), Relatives $(\beta=0.23, p<0.001 ;$ large effect size $)$ and Neighbours $\beta=0.2, p<0.001$; moderate effect size; see Supplementary Materials). Inspecting the paths within these models indicated that mediation effects were likely to be small in magnitude similarly to those found in the above analysis including Extraversion as a predictor.

\section{Discussion}

We hypothesised that social support would mediate the relationships between personality and cognitive function. Significant mediation effects of social 
support were evident in the relationships between Extraversion, Neuroticism, and global cognitive function, supporting both hypotheses. Our aim in the current study was twofold. First we wished to address the absence of individual level factors in recent analyses relating to social support and health outcomes ${ }^{31}$. We found here evidence that inclusion of individual level factors such as Personality is informative when evaluating and quantifying the association between social support and health outcomes. The thrust of our second aim was to respond to calls made by Austin to further investigate mechanisms through which personality may impact cognitive function ${ }^{30}$. Our results indicate that social support is merits further investigation in relation to mechanisms through which personality impacts cognitive function.

A direct negative effect between Extraversion and cognitive function was evident, controlling for baseline cognitive function. This runs counter to our hypothesis and suggests that individuals with low levels of Extraversion have the highest levels of cognitive function in the current sample, although the magnitude of this effect was relatively small. Our finding reflects some previous findings ${ }^{17}$, but not others $^{16,18,19}$. Having higher levels of Extraversion was associated with higher levels of social support at follow-up (although this effect was small in magnitude and trending only in significance). The presence of the mediation effect indicates that Extraversion accounts directly for a small proportion of variance in cognitive function, and it is associated with social support, which accounts for a larger proportion of the variance in cognitive function. The mediation effect found was inconsistent in nature, such that the overall effect of Extraversion on cognitive function was negative, but the effect via social support was positive. . It is possible that certain facets of Extraversion are driving this inconsistent mediation, while other facets could impact in more positive ways on Extraversion. Decomposing the effect of different facets of Extraversion on cognitive function may be a logical next step for future research.

Decomposing the social support scale into three subscales (support from relatives, friends, and neighbours) revealed small, significant mediation effects through all three scales. While not all paths within these mediation models were significant, it has been argued by prominent writers in mediation research that these paths must be different to zero, rather than having statistical significance, in order 
for mediation to be present ${ }^{42}$. The same writer warns against over-reliance on statistical significance testing as a decision criterion in mediation analyses ${ }^{42}$. Inspecting the magnitude of the paths showed small mediation effects via the three subscales for the relationship between Extraversion and cognitive function. Extraversion is positively related to all three subscales, while social support from relatives and friends was positively associated with cognitive function outcomes and social support from neighbours was negatively associated (and not statistically significant). This finding is interesting in light of speculation that receipt of support from different sources has different impacts on health outcomes ${ }^{43}$; perhaps receipt of support from neighbours is more likely to occur in more dependent, less healthy individuals, who are more likely to be cognitively impaired than the general older population.

Neuroticism was not associated with cognitive function at follow-up. Social support may mediate the relationship between Neuroticism at baseline and cognitive function at follow-up, controlling for baseline cognitive function, but in the absence of a direct effect. The total effect of Neuroticism on cognitive function (including the mediator) was positive, while Neuroticism had a negative (trending, small) association with social support, indicating that the majority of the total effect was composed of the positive association between social support and cognitive function. While Neuroticism does not have a direct effect on cognitive function, it does possibly lead to lower levels of social support, which lead to lower levels of social support. However, the contribution of Neuroticism here is very small.

Decomposing the mediation effect into three mediating pathways (social support from relatives, neighbours, and friends) found very small but significant mediation effects such that Neuroticism had small, non-significant negative associations with all three subscales. Social support from relatives and friends had small positive associations with cognitive functioning while social support from neighbours had a very small, non-significant and negative association with cognitive functioning (as seen in the previous model with Extraversion as the predictor). The size of the effects merit caution in over-interpreting the results, but it appears there are small mediation effects in play here, particularly via social support from friends and relatives. 
Our results indicate that mediation effects are detectable but small within the models, and the instability in the relationship between personality and cognitive function over time may implicate random error. Repeated measurements over a longer time period would be required to fully understand the association between personality and cognitive function, and whether it is mediated in part by social support. Using the half-longitudinal mediation approach is preferable to using crosssectional data but it can lead to spurious mediation effects if the assumption of stationarity is violated ${ }^{44}$. That is to say, we assume that the impact of social support on cognitive functioning is the same between waves 1 and 2 as it would be between wave 2 and a hypothetical wave 3 . That said, we advocate its use and careful consideration of issues related to mediation analysis in personality research, since it could further our understanding of the impact of personality not just on cognitive function but also on other biopsychosocial outcomes.

Further exploration of potential mechanisms sub-serving this association as recommended ${ }^{20}$ would be worthwhile, since inclusion of other relevant variables may help to give a more comprehensive account of the personality-cognitive function relationship. Another aspect of the current analysis which merits caution in interpretation is the nature of the sample described. These individuals were recruited via convenience sampling and were medically stable, and living independently in the community, and therefore may have had favourable cognitive, personality, and social support profiles, relative to a less healthy older population. However, in a recent point-counterpoint, Rothman and colleagues argued that when the goal of an epidemiologic research question is generalizing about disease processes, representative sampling can detract from our ability to identify causal effects and explain how they influence health ${ }^{45}$.

In addition, we urge some caution in interpreting our model results, since some indices of model fit were relatively poor. One would expect a chi-squared measure of fit to be statistically non-significant in a sample size as large as that of the current study, but it is nevertheless convention to report this figure. The CFI index indicated a good fit for all models, in contrast to the TLI measure. The TLI enforces penalty for the number of parameters specified, and in considering our pattern of results, it is worth reflecting on current advice ${ }^{46}$, which recommends 
assessing g the chi-squared test, the RMSEA, the CFI and the SRMR. Our RMSEA in all models was also indicative of a poor fit. The RMSEA also penalizes complexity, which may be why the current model had a poor RMSEA but acceptable SRMR and CFI. Reliability of the personality scales was lower than threshold acceptability, which also warrants caution in model interpretation.

We used a global measure of cognitive function rather than measures of cognitive domains. Future research should investigate whether social support mediates the relationship between personality and these cognitive domains. Also, the same cognitive measure was administered at baseline and follow-up, so practice effects may lead to underestimation of true cognitive declines. Typically investigating practice effects involves comparing individuals being tested for the first time with those being tested for the second time ${ }^{47}$, which was not possible given our study design. However, in the current analysis, we were interested in the association between personality and cognitive function, rather than with cognitive decline.

Furthermore, due to study constraints we focused our analysis on two personality traits. The Five Factor Model ${ }^{48}$ also considers Openness, Conscientiousness, and Agreeableness, which have previously been linked to cognitive outcomes ${ }^{29}$. Further analysis considering these three traits would broaden our understanding of the mechanisms linking personality to cognitive function.

To conclude, we report that older adults with high levels of Extraversion have lower cognitive function at follow-up. We found no evidence of an association between Neuroticism and cognitive function at follow-up. We also find support for the hypothesis that social support partially mediates the link between personality and cognitive functioning. Since personality is thought to be relatively stable through the lifespan, social support may represent an intervention target for older adults who, because of their personality profile, are at risk of cognitive decline. Based on our results, intervention on social support from friends and relatives may be more successful than intervening on social support levels from neighbours. Interventions may consider identifying at-risk individuals by using personality scales to those who would benefit from increases in social support. It is those individuals who are high in 
Extraversion, in particular, who would stand to benefit from increased social support, in relation to cognitive outcomes.

\section{Acknowledgements}

We wish to thank the research team at the Technology Research for Independent Living Centre (TRIL) and all participants who were engaged in the current study.

Funding: This work was supported by a fellowship received by J McHugh Power from the Centre for Ageing Research \& Development in Ireland. The TRIL Centre received funding from Intel Ireland, the Industrial Development Agency (IDA Ireland), and GE Healthcare.

Competing interests: None Declared.

Ethical approval: Given by the Research Ethics Committee at St James's Hospital and Trinity College Dublin. 


\section{References}

1. Anstey KJ, von sanden C, Salim A, O'Kearney R. Smoking as a risk factor for dementia and cognitive decline: A meta-analysis of prospective studies. American Journal of Epidemiology. 2007; 166:367-78.

2. Yaffe K, Kanaya A, Lindquist K, Simonsick EM, Harris TB, Shorr R, et al. The metabolic syndrome, inflammation, and risk of cognitive decline Journal of the American Medical Association. 2004; 292:2237-42.

3. Yaffe K, Barnes D, Nevitt M, Lui LY, Covinsky K. A prospective study of physical activity and cognitive decline in elderly women: women who walk. Archives of internal medicine. 2001; 161:1703-8.

4. Jorm AF. Is depression a risk factor for dementia or cognitive decline? Gerontology. 2000; 46:219-27.

5. Stern Y. What is cognitive reserve? Theory and research application of the reserve concept. Journal of the International Neuropsychological Society. 2002; 8:448-60.

6. Zhang M, Gale SD, Erickson LD, Brown BL, Woody P, Hedges DW. Cognitive function in older adults according to current socioeconomic status. Aging, Neuropsychology, and Cognition. 2015:1-10.

7. van Gelder BM, Tijhuis M, Kalmijn S, Giampaoli S, Nissinen A, Kromhout D. Marital Status and Living Situation During a 5-Year Period Are Associated With a Subsequent 10-Year Cognitive Decline in Older Men: The FINE Study. The Journals of Gerontology Series B: Psychological Sciences and Social Sciences. 2006; 61:P213-P9.

8. Green AF, Rebok G, Lyketsos CG. Influence of social network characteristics on cognition and functional status with aging. International journal of geriatric psychiatry. 2008; 23:972-8.

9. DiNapoli EA, Wu B, Scogin F. Social Isolation and Cognitive Function in Appalachian Older Adults. Research on Aging. 2014; 36:161-79.

10. Bennett DA, Schneider JA, Tang Y, Arnold SE, Wilson RS. The effect of social networks on the relation between Alzheimer's disease pathology and level of cognitive function in old people: a longitudinal cohort study. The Lancet Neurology. 2006; 5:406-12.

11. Eysenck H, Eysenck MW. Personality and Individual Differences: A Natural Science Approach. New York: Plenum; 1985.

12. Costa PT, Fozard JL, McCrae RR, Bossé R. Relations of Age and Personality Dimensions to Cognitive Ability Factors. Journal of gerontology. 1976; 31:663-9. 13. Suurmeijer T, van Sonderen F, Krol B, Doeglas D, van den Huevel W, Sanderman R. The relationship between personality, supportive transactions, and support satisfaction, and mental health of patients with early rheumatoid arthritis, results from the Dutch part of the Euridiss study. Social Indicators Research. 2004; 73:179-97.

14. DeYoung CG. Cybernetic Big Five Theory. Journal of REsearch in Personality. 2015; 56:33-58.

15. Allen PA, Kaut K, Baena E, Lien M, Ruthruff E. Individual differences in positive affect moderate age-related declines in episodic long-term memory. Journal of Cognitive Psychology. 2011; 23:768-79.

16. Crowe M, Andel R, Pedersen NL, Fratiglioni L, Gatz M. Personality and risk of cognitive impairment 25 years later. Psychol Aging. 2006; 21:573-80. 
17. Luchetti M, Terracciano A, Stephan Y, Sutin AR. Personality and cognitive decline in older adults: Data from a longitudinal sample and meta-analysis Journals of Gerontology B: Psychological Sciences. 2015; 71:591-601.

18. Booth JE, Schinka JA, Brown LM, Mortimer JA, Borenstein AR. Five-factor personality dimensions, mood states, and cognitive performance in older adults. Journal of clinical and experimental neuropsychology. 2006; 28:676-83.

19. Wolf MB, Ackerman PL. Extraversion and Intelligence: A meta-analytic investigation. Personality and Individual Differences. 2005; 39:531-42.

20. Curtis RG, Windsor TD, Soubelet A. The relationship between Big-5 personality traits and cognitive ability in older adults - a review. Aging, Neuropsychology \& Cognition. 2015; 22:42-71.

21. Bolger N, Eckenrode J. Social relationships, personality, and anxiety during a major stressful event. Journal of Personality and Social Psychology. 1991; 61:440-9.

22. Hull JG, Tedlie JC, Lehn DA. Modeling the relation of personality variables to symptom complaints: The unique role of negative affectivity. In: Hoyle RH, editor. Structural equation modeling: Concepts, issues, and applications. Thousand Oaks, CA: Sage; 1995. p. 217-35.

23. Finch JF, Graziano WG. Predicting depression from temperament, personality, and patterns of social relations. Journal of Personality 2001; 69:2755.

24. Graham EK, Lachman ME. Personality stability is associated with better cognitive performance in adulthood: are the stable more able? The journals of gerontology Series B, Psychological sciences and social sciences. 2012; 67:54554 .

25. SAPOLSKY RM, KREY LC, McEWEN BS. The Neuroendocrinology of Stress and Aging: The Glucocorticoid Cascade Hypothesis. Endocrine Reviews. 1986; 7:284-301.

26. Mangold DL, Wand GS. Cortisol and adrenocorticotropic hormone responses to naloxone in subjects with high and low neuroticism. Biological Psychiatry. 2006; 60:850-5.

27. Ziegler M, Cengia A, Mussel P, Gerstorf D. Openness as a buffer against cognitive decline: The Openness-Fluid-Crystallised-Intelligence (OFCI) model applied to late adulthood. Psychology \& Aging. 2015; 30:573-88.

28. Chapman B, Duberstein PR, Tindle HA, Sink KM, Robbins J, Tancredi DJ, et al. Personality predicts cognitive function over 7 years in older persons. American Journal of Geriatric Psychiatry. 2012; 20:612-21.

29. Baker TJ, Bischel J. Personality predictors of intelligence: Differences between young and cognitively healthy older adults. Personality and Individual Differences. 2006; 41:861-71.

30. Austin EJ, Deary IJ, Whiteman MC, Fowkes FGR, Pedersen NL, Rabbitt P, et al. Relationships between ability and personality: Does intelligence contribute positively to personal and social adjustment? . Personality and Individual Differences. 2002; 32:1391-411.

31. Milner A, Krnjacki L, LaMontagne AD. Age and gender differences in the influence of social support on mental health: a longitudinal fixed-effects analysis using 13 annual waves of the HILDA cohort. Public Health. 2016; 140:172-8.

32. Power JM, Carney S, Hannigan C, Brennan S, Wolfe H, Lynch M, et al. Systemic inflammatory markers and sources of social support among older 
adults in the Memory Research Unit cohort. Journal of Health Psychology. 2016:1359105316676331.

33. Eysenck H, Eysenck S. Eysenck Personality Questionnaire: Revised (EPQR). London: Hodder \& Stoughton; 1991.

34. Alexopoulos DS, Kalaitzidis I. Psychometric properties of the Eysenck Personality Questionnaire (EPQ-R) short scale in Greece. . Personality and Individual Differences. 2003; 37:1205-20.

35. Lubben J, Gironda M. Measuring social networks and assessing their benefits. In: Phillipson C, Allan G, Morgan D, editors. Social Networks and Social Exclusion: Sociological and Policy Perspective. Boston: Ashgate; 2004.

36. Folstein MF, Folstein SE, McHugh PR. 'Mini-Mental State': A practical method for grading the cognitive state of patients for the clinician. Journal of psychiatric research. 1975; 12:189-98.

37. Cullen B, Fahy S, Cunningham C, Coen R, Bruce I, Greene E, et al. Screening for dementia in an Irish community sample using MMSE: a comparison of normadjusted versus fixed cut-points. International journal of geriatric psychiatry. 2005; 20:371-6.

38. Tombaugh TN, McIntyre NJ. The mini-mental state examination: A comprehensive review. Journal of the American Geriatrics Society. 1992; 40:92235.

39. Rosseel Y. lavaan: An R Package for Structural Equation Modeling. Journal of Statistical Software 2012; 48:1-36.

40. Cole DA, Maxwell SE. Testing mediational models with longitudinal data: Questions and tips in the use of structural equation modelling. Journal of Abnormal Psychology. 2003; 112:558-77.

41. MacCallum RC, Browne MW, Sugawara HM. Power analysis and determination of sample size for covariance structure modeling. Psychological Methods. 1996; 1:130-49.

42. Kline RB. The mediation myth. Basic and Applied Social Psychology. 2015; 37:202-13.

43. DuPertuis LL, Aldwin CM, Bosse R. Does the source of support matter for different health outcomes? Findings from the Normative Aging Study. Journal of Aging and Health. 2001; 13:494-510.

44. Gollub HF, Reichardt CS. Building time lags into causal models of cross sectional data. In: Association AS, editor. American Statistical Association Proceedings in Social Statistics; Washington, DC: American Statistical Association 1985.

45. Rothman KJ, Gallacher JE, Hatch EE. Why representativeness should be avoided. International Journal of Epidemiology. 2013; 42:1012-4.

46. Kline R. Principles and practice of structural equation modelling. UK: Guilford Press; 2005.

47. Salthouse TA. Influence of age on practice effects in longitudinal neurocognitive change. Neuropsychology. 2010; 24:563-72.

48. Costa PT, McCrae RR. Revised NEO Personality Inventory (NEOPIR) and NEO Five Factor (NEO FFI) Inventory Professional Manual. Odessa, Florida: PAR 1992. 


\section{Figure Legends}

Figure 1. Mediation Model with Extraversion as Predictor, Social support as Mediator, and Cognitive Function as the Outcome.

Figure 2. Mediation Model with Neuroticism as Predictor, Social support as Mediator, and Cognitive Function as the Outcome. 
Supplementary Materials Table 1. Results from the Structural Equation Model, using the "half-longitudinal" mediation design approach (Cole \& Maxwell, 2003) with Extraversion as the exposure variable, cognitive function (MMSE at time 2) as the outcome, and Social Support subscale scores (LSNS Relatives, LSNS Neighbours, LSNS Friends) as the mediators (and age, gender, and education level as covariates).

\begin{tabular}{|c|c|c|c|c|c|c|}
\hline & $\begin{array}{l}\text { Unstandardised } \\
\text { Estimate }\end{array}$ & Beta & $\begin{array}{l}\text { Standard } \\
\text { Error }\end{array}$ & Z & $\mathrm{p}$ & $\mathrm{Cl}_{95}$ \\
\hline \multicolumn{7}{|c|}{ Regression with MMSE at Time 2 as Outcome } \\
\hline Extraversion & -0.06 & -0.1 & 0.03 & -2.41 & 0.05 & $\begin{array}{l}-0.12,- \\
0.01\end{array}$ \\
\hline Age & -0.07 & -0.18 & 0.02 & -4.76 & $<0.001$ & $\begin{array}{l}-0.01,- \\
0.05\end{array}$ \\
\hline Gender & 0.40 & 0.07 & 0.21 & 1.92 & 0.055 & $\begin{array}{l}-0.01 \\
0.81\end{array}$ \\
\hline $\begin{array}{l}\text { Education } \\
\text { Level }\end{array}$ & 0.19 & 0.09 & 0.09 & 2.18 & $<0.05$ & $\begin{array}{l}0.02 \\
0.37\end{array}$ \\
\hline $\begin{array}{l}\text { LSNS } \\
\text { Relatives at } \\
\text { Time } 1\end{array}$ & -0.02 & -0.04 & 0.02 & -0.91 & $>0.05$ & $\begin{array}{l}-0.07 \\
0.03\end{array}$ \\
\hline $\begin{array}{l}\text { LSNS } \\
\text { Neighbours } \\
\text { at Time } 1\end{array}$ & 0.02 & 0.04 & 0.02 & 0.78 & $>0.05$ & $\begin{array}{l}-0.02 \\
0.06\end{array}$ \\
\hline $\begin{array}{l}\text { LSNS Friends } \\
\text { at Time } 1\end{array}$ & -0.03 & -0.08 & 0.02 & -1.69 & 0.09 & $\begin{array}{l}-0.07,- \\
0.01\end{array}$ \\
\hline $\begin{array}{l}\text { MMSE at } \\
\text { Time } 1\end{array}$ & 0.61 & 0.5 & 0.05 & 12.21 & $<0.001$ & $\begin{array}{l}0.51 \\
0.71\end{array}$ \\
\hline $\begin{array}{l}\text { LSNS } \\
\text { Relatives at } \\
\text { Time } 2\end{array}$ & 0.05 & 0.1 & 0.02 & 2.19 & $<0.05$ & $\begin{array}{l}0.01 \\
0.09\end{array}$ \\
\hline $\begin{array}{l}\text { LSNS } \\
\text { Neighbours } \\
\text { at Time } 2\end{array}$ & -0.02 & -0.06 & 0.02 & -1.31 & $>0.05$ & $\begin{array}{l}-0.06 \\
0.01\end{array}$ \\
\hline $\begin{array}{l}\text { LSNS Friends } \\
\text { at Time } 2\end{array}$ & 0.05 & 0.13 & 0.02 & 2.68 & $<0.01$ & $\begin{array}{l}0.01 \\
0.08\end{array}$ \\
\hline \multicolumn{7}{|c|}{ Regression with LSNS Relatives at Time 2 as Outcome } \\
\hline $\begin{array}{l}\text { LSNS } \\
\text { Relatives at } \\
\text { Time } 1\end{array}$ & 0.61 & 0.57 & 0.04 & 14.83 & $<0.001$ & $\begin{array}{l}0.53 \\
0.69\end{array}$ \\
\hline Extraversion & 0.02 & 0.01 & 0.05 & 0.27 & $>0.05$ & $\begin{array}{l}-0.01,- \\
0.12\end{array}$ \\
\hline \multicolumn{7}{|c|}{ Regression with LSNS Neighbours at Time 2 as Outcome } \\
\hline $\begin{array}{l}\text { LSNS } \\
\text { Neighbours } \\
\text { at Time } 1\end{array}$ & 0.47 & 0.43 & 0.05 & 10.14 & $<0.001$ & $\begin{array}{l}0.38 \\
0.56\end{array}$ \\
\hline Extraversion & 0.16 & 0.11 & 0.07 & 2.39 & $<0.05$ & $\begin{array}{l}0.03 \\
0.29\end{array}$ \\
\hline
\end{tabular}




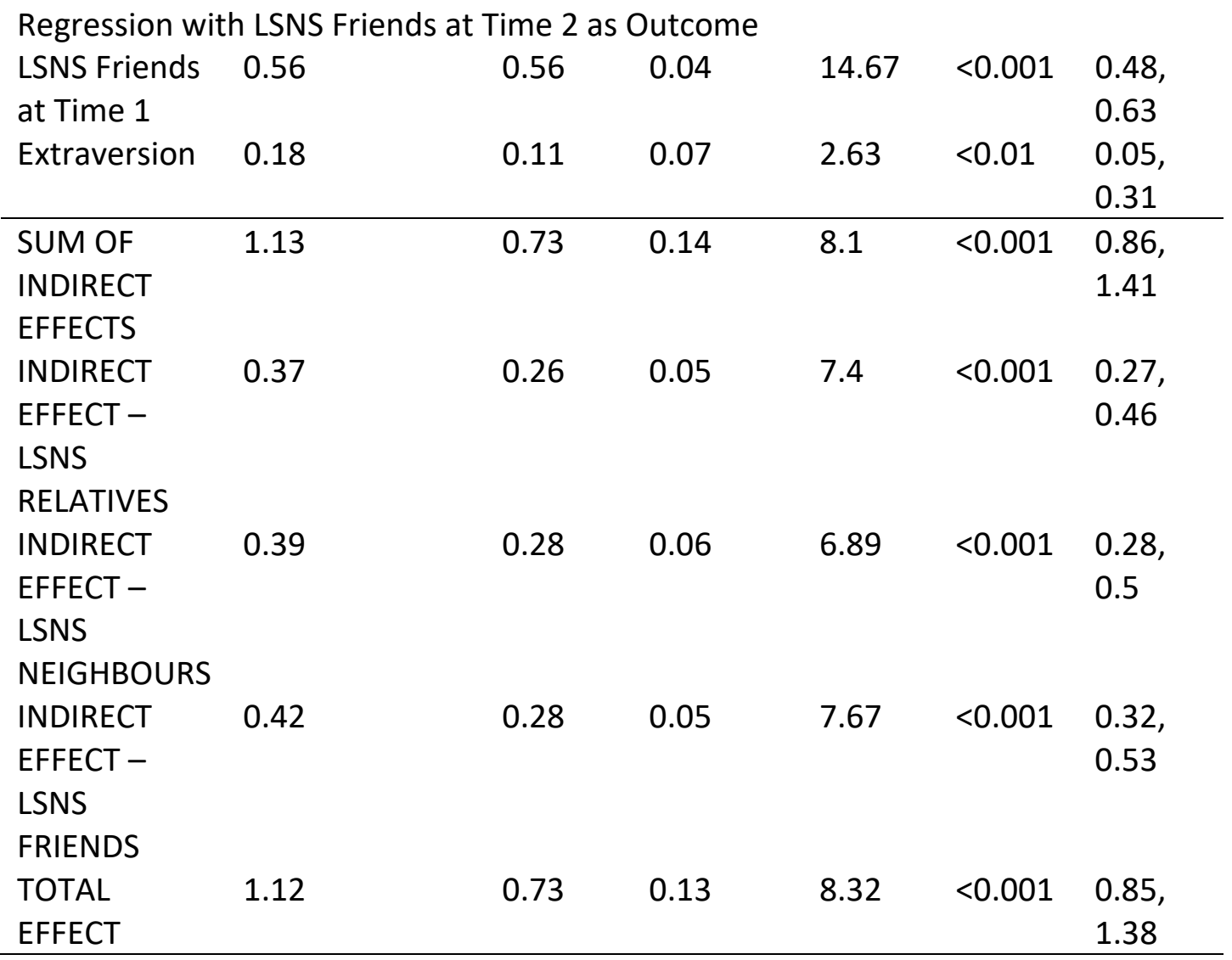


Table 1. Baseline and Follow-up Characteristics of Sample With Means and Standard Deviations (SD) Given Where Data are Continuous, and Frequencies Given Where Data are Categorical.

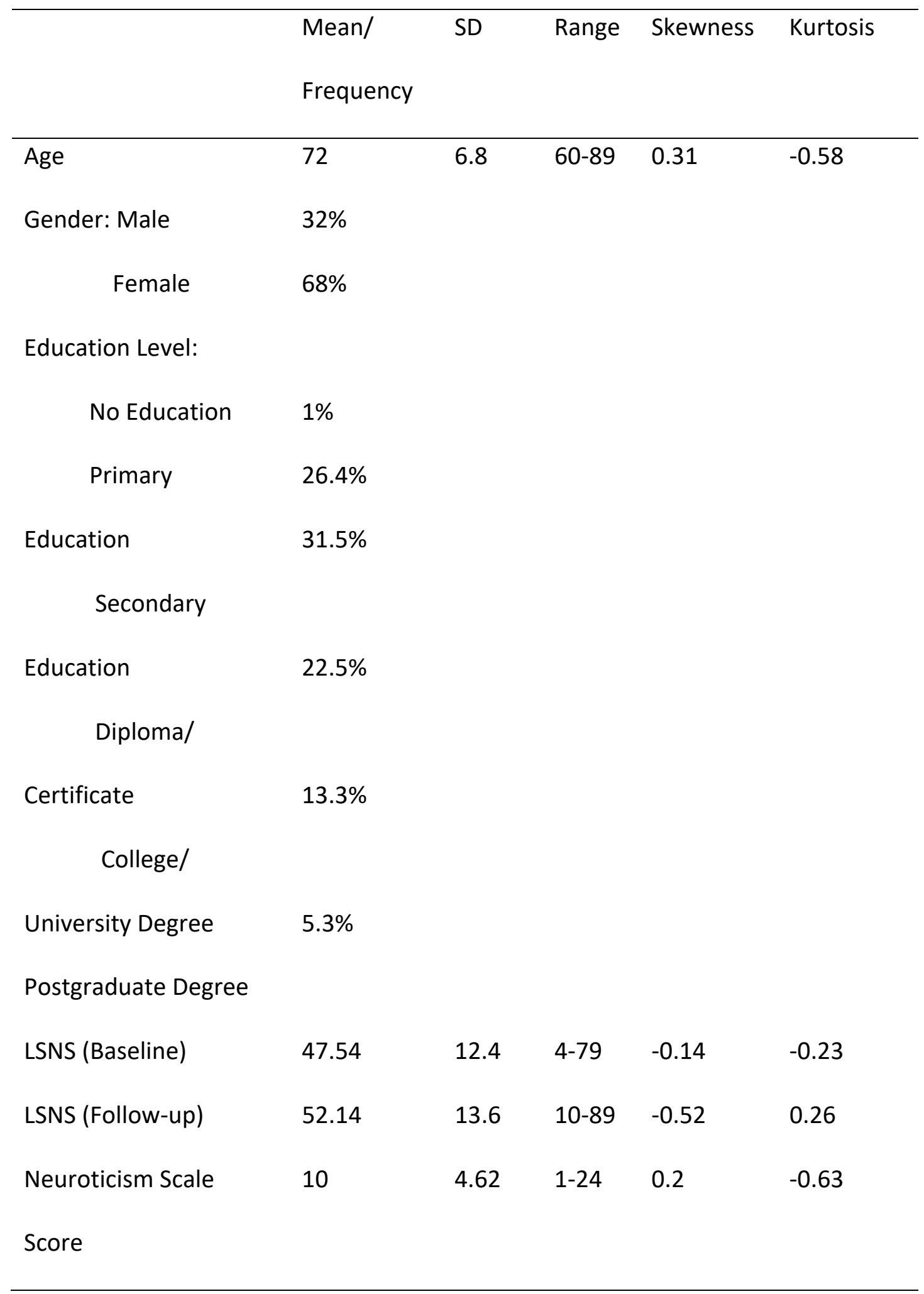




\begin{tabular}{lccccc}
\hline Extraversion Scale & 11.53 & 4.07 & $2-23$ & 0.11 & -0.55 \\
Score & & & & & \\
MMSE Score (Baseline) & 27.61 & 2.13 & $18-30$ & -1.34 & 2.35 \\
MMSE Score (Follow- & 27.32 & 2.64 & $12-30$ & -1.83 & 4.76 \\
up) & & & & & \\
\hline
\end{tabular}

Table 2. Correlation Matrix for Measures in the TRIL Cohort $(n=$, using Spearman Correlations $(*$ indicates $p<0.05 ; * *$ indicates $p<0.01 ; * * *$ indicates $p<0.001)$. LSNS $=$ Lubben Social Support Network Scale (Lubben \& Gironda, 2004); MMSE = Mini Mental State Examination (Folstein et al., 1975); Neuro = scores on the Neuroticism Scale (Eysenck \& Eysenck, 1985); Extrav = scores on the Extraversion scale (Eysenck \& Eysenck, 1985).

\begin{tabular}{|c|c|c|c|c|c|c|c|}
\hline & Age & $\begin{array}{l}\text { MMSE } \\
\text { Time } 1\end{array}$ & $\begin{array}{l}\text { MMSE } \\
\text { Time } 2\end{array}$ & Neuro & Extrav & $\begin{array}{l}\text { LSNS } \\
\text { Time } 1\end{array}$ & $\begin{array}{l}\text { LSNS } \\
\text { Time } 2\end{array}$ \\
\hline Age & 1.00 & & & & & & \\
\hline $\begin{array}{l}\text { MMSE } \\
\text { Time } 1\end{array}$ & $-0.21 * * *$ & 1.00 & & & & & \\
\hline $\begin{array}{l}\text { MMSE } \\
\text { Time } 2\end{array}$ & $-0.32 * * *$ & $0.59 * * *$ & 1.00 & & & & \\
\hline
\end{tabular}




\begin{tabular}{|c|c|c|c|c|c|c|c|}
\hline Neuro & 0.05 & -0.09 & -0.04 & 1.00 & & & \\
\hline Extrav & -0.03 & -0.04 & $-0.11^{*}$ & $-0.1^{*}$ & 1.00 & & \\
\hline $\begin{array}{l}\text { LSNS } \\
\text { Time } 1\end{array}$ & $-0.22 * * *$ & $0.11^{* * *}$ & $0.13^{* *}$ & $-0.11^{*}$ & $0.31 * * *$ & 1.00 & \\
\hline $\begin{array}{l}\text { LSNS } \\
\text { Time } 2\end{array}$ & $-0.26 * * *$ & $0.27 * * *$ & $0.26 * * *$ & $-0.14 * *$ & $0.26 * * *$ & $0.61 * * *$ & 1.00 \\
\hline
\end{tabular}

Table 3. Results from the Structural Equation Model, using the "half-longitudinal" mediation design approach (Cole \& Maxwell, 2003) with Extraversion as the exposure variable, cognitive function (MMSE at time 2) as the outcome, and Social Support scale scores (LSNS) as the mediator (and age, gender, and education level as covariates).

\begin{tabular}{|c|c|c|c|c|c|c|}
\hline & $\begin{array}{l}\text { Unstandardised } \\
\text { Estimate }\end{array}$ & Beta & $\begin{array}{l}\text { Standard } \\
\text { Error }\end{array}$ & Z & $p$ & $\mathrm{Cl}_{95}$ \\
\hline \multicolumn{7}{|c|}{ Regression with MMSE at Time 2 as Outcome } \\
\hline Extraversion & -0.07 & -0.11 & 0.03 & -2.55 & $<0.01$ & $\begin{array}{l}-0.12 \\
0.02\end{array}$ \\
\hline Age & -0.07 & -0.19 & 0.02 & -4.87 & $<0.001$ & $\begin{array}{l}-0.1,- \\
0.04\end{array}$ \\
\hline Gender & 0.399 & 0.07 & 0.21 & 1.94 & 0.053 & $\begin{array}{l}-0.01 \\
0.8\end{array}$ \\
\hline $\begin{array}{l}\text { Education } \\
\text { Level }\end{array}$ & 0.17 & 0.08 & 0.09 & 1.9 & 0.057 & $\begin{array}{l}-0.01 \\
0.34\end{array}$ \\
\hline $\begin{array}{l}\text { LSNS at } \\
\text { Time } 1\end{array}$ & -0.01 & -0.05 & 0.01 & -1.02 & $>0.05$ & $\begin{array}{l}-0.03 \\
0.01\end{array}$ \\
\hline $\begin{array}{l}\text { MMSE at } \\
\text { Time } 1\end{array}$ & 0.61 & 0.5 & 0.05 & 12.31 & $<0.001$ & $\begin{array}{l}0.51 \\
0.71\end{array}$ \\
\hline $\begin{array}{l}\text { LSNS at } \\
\text { Time } 2\end{array}$ & 0.02 & 0.12 & 0.01 & 2.42 & $<0.05$ & $\begin{array}{l}0.004 \\
0.04\end{array}$ \\
\hline \multicolumn{7}{|c|}{ Regression with LSNS at Time 2 as Outcome } \\
\hline $\begin{array}{l}\text { LSNS at } \\
\text { Time } 1\end{array}$ & 0.65 & 0.59 & 0.04 & 14.89 & $<0.001$ & $\begin{array}{l}-0.56 \\
0.73\end{array}$ \\
\hline Extraversion & 0.24 & 0.07 & 0.14 & 1.76 & 0.07 & $\begin{array}{l}-0.03 \\
0.51\end{array}$ \\
\hline
\end{tabular}




\begin{tabular}{lllllll}
\hline INDIRECT & 0.53 & 0.3 & 0.09 & 5.95 & $<0.001$ & 0.36, \\
EFFECT & & & & & & 0.71 \\
TOTAL & 0.46 & 0.19 & 0.09 & 4.9 & $<0.001$ & 0.28, \\
EFFECT & & & & & & 0.65 \\
\hline
\end{tabular}

Table 4. Results from the Structural Equation Model, using the "half-longitudinal" mediation design approach (Cole \& Maxwell, 2003) with Neuroticism as the exposure variable, cognitive function (MMSE at time 2 ) as the outcome, and Social Support scale scores (LSNS) as the mediator (and age, gender, and education level as covariates).

\begin{tabular}{|c|c|c|c|c|c|c|}
\hline & $\begin{array}{l}\text { Unstandardised } \\
\text { Estimate }\end{array}$ & Beta & $\begin{array}{l}\text { Standard } \\
\text { Error }\end{array}$ & Z & $p$ & $\mathrm{Cl}_{95}$ \\
\hline \multicolumn{7}{|c|}{ Regression with MMSE at Time 2 as Outcome } \\
\hline Neuroticism & 0.01 & 0.02 & 0.02 & 0.51 & 0.61 & $\begin{array}{l}-0.03 \\
0.06\end{array}$ \\
\hline Age & -0.07 & -0.19 & 0.02 & -4.91 & $<0.001$ & $\begin{array}{l}-0.1,- \\
0.04\end{array}$ \\
\hline Gender & 0.4 & 0.07 & 0.21 & 1.93 & 0.054 & $\begin{array}{l}-0.01 \\
0.81\end{array}$ \\
\hline $\begin{array}{l}\text { Education } \\
\text { Level }\end{array}$ & 0.2 & 0.09 & 0.09 & 2.29 & $<0.05$ & $\begin{array}{l}0.03 \\
0.38\end{array}$ \\
\hline $\begin{array}{l}\text { LSNS at } \\
\text { Time } 1\end{array}$ & -0.02 & -0.07 & 0.01 & -1.59 & 0.11 & $\begin{array}{l}-0.04 \\
0.004\end{array}$ \\
\hline $\begin{array}{l}\text { MMSE at } \\
\text { Time } 1\end{array}$ & 0.62 & 0.51 & 0.05 & 12.47 & $<0.001$ & $\begin{array}{l}0.52 \\
0.72\end{array}$ \\
\hline $\begin{array}{l}\text { LSNS at } \\
\text { Time } 2\end{array}$ & 0.02 & 0.10 & 0.01 & 2.11 & $<0.05$ & $\begin{array}{l}0.001 \\
0.04\end{array}$ \\
\hline \multicolumn{7}{|c|}{ Regression with LSNS at Time 2 as Outcome } \\
\hline $\begin{array}{l}\text { LSNS at } \\
\text { Time } 1\end{array}$ & 0.66 & 0.6 & 0.04 & 15.99 & $<0.001$ & $\begin{array}{l}0.58 \\
0.74\end{array}$ \\
\hline Neuroticism & -0.21 & -0.07 & 0.12 & 2.11 & 0.06 & $\begin{array}{l}-0.44 \\
0.01\end{array}$ \\
\hline $\begin{array}{l}\text { INDIRECT } \\
\text { EFFECT }\end{array}$ & 0.27 & 0.23 & 0.08 & 3.39 & $<0.01$ & $\begin{array}{l}0.12 \\
0.43\end{array}$ \\
\hline $\begin{array}{l}\text { TOTAL } \\
\text { EFFECT }\end{array}$ & 0.28 & 0.25 & 0.08 & 3.37 & $<0.01$ & $\begin{array}{l}0.12 \\
0.45\end{array}$ \\
\hline
\end{tabular}


Supplementary Materials Table 2. Results from the Structural Equation Model, using the "half-longitudinal" mediation design approach (Cole \& Maxwell, 2003) with Neuroticism as the exposure variable, cognitive function (MMSE at time 2) as the outcome, and Social Support subscale scores (LSNS Relatives, LSNS Neighbours, LSNS Friends) as the mediators (and age, gender, and education level as covariates).

\begin{tabular}{|c|c|c|c|c|c|c|}
\hline & $\begin{array}{l}\text { Unstandardised } \\
\text { Estimate }\end{array}$ & Beta & $\begin{array}{l}\text { Standard } \\
\text { Error }\end{array}$ & Z & $\mathrm{p}$ & $\mathrm{Cl}_{95}$ \\
\hline \multicolumn{7}{|c|}{ Regression with MMSE at Time 2 as Outcome } \\
\hline Neuroticism & 0.01 & 0.02 & 0.02 & 0.54 & $>0.05$ & $\begin{array}{l}-0.03 \\
0.06\end{array}$ \\
\hline Age & -0.07 & -0.19 & 0.02 & -4.82 & $<0.001$ & $\begin{array}{l}-0.1,- \\
0.04\end{array}$ \\
\hline Gender & 0.41 & 0.07 & 0.21 & 1.96 & 0.05 & $0,0.83$ \\
\hline $\begin{array}{l}\text { Education } \\
\text { Level }\end{array}$ & 0.23 & 0.1 & 0.09 & 2.58 & $<0.05$ & $\begin{array}{l}0.05 \\
0.4\end{array}$ \\
\hline $\begin{array}{l}\text { LSNS } \\
\text { Relatives at } \\
\text { Time } 1\end{array}$ & -0.03 & -0.05 & 0.03 & -1.11 & $>0.05$ & $\begin{array}{l}-0.08 \\
0.02\end{array}$ \\
\hline $\begin{array}{l}\text { LSNS } \\
\text { Neighbours } \\
\text { at Time } 1\end{array}$ & 0.01 & 0.02 & 0.02 & 0.49 & $>0.05$ & $\begin{array}{l}-0.03 \\
0.05\end{array}$ \\
\hline $\begin{array}{l}\text { LSNS Friends } \\
\text { at Time } 1\end{array}$ & -0.04 & -0.09 & 0.02 & -1.94 & 0.05 & $-0.07,0$ \\
\hline $\begin{array}{l}\text { MMSE at } \\
\text { Time } 1\end{array}$ & 0.62 & 0.51 & 0.05 & 12.37 & $<0.001$ & $\begin{array}{l}0.52 \\
0.72\end{array}$ \\
\hline $\begin{array}{l}\text { LSNS } \\
\text { Relatives at } \\
\text { Time } 2\end{array}$ & 0.05 & 0.11 & 0.02 & 2.31 & $<0.05$ & $\begin{array}{l}0.01 \\
0.09\end{array}$ \\
\hline $\begin{array}{l}\text { LSNS } \\
\text { Neighbours } \\
\text { at Time } 2\end{array}$ & -0.03 & -0.07 & 0.02 & -1.53 & $>0.05$ & $\begin{array}{l}-0.07 \\
0.01\end{array}$ \\
\hline $\begin{array}{l}\text { LSNS Friends } \\
\text { at Time } 2\end{array}$ & 0.05 & 0.12 & 0.02 & 2.38 & $<0.05$ & $\begin{array}{l}0.01 \\
0.08\end{array}$ \\
\hline \multicolumn{7}{|c|}{ Regression with LSNS Relatives at Time 2 as Outcome } \\
\hline $\begin{array}{l}\text { LSNS } \\
\text { Relatives at } \\
\text { Time } 1\end{array}$ & 0.6 & 0.56 & 0.04 & 14.6 & $<0.001$ & $\begin{array}{l}0.52 \\
0.68\end{array}$ \\
\hline Neuroticism & -0.06 & -0.06 & 0.05 & -1.36 & 0.174 & $\begin{array}{l}-0.16 \\
0.03\end{array}$ \\
\hline \multicolumn{7}{|c|}{ Regression with LSNS Neighbours at Time 2 as Outcome } \\
\hline $\begin{array}{l}\text { LSNS } \\
\text { Neighbours } \\
\text { at Time } 1\end{array}$ & 0.49 & 0.45 & 0.05 & 10.88 & $<0.001$ & $\begin{array}{l}0.4 \\
0.58\end{array}$ \\
\hline Neuroticism & -0.09 & -0.07 & 0.06 & -1.49 & $>0.05$ & $\begin{array}{l}-0.2 \\
0.03\end{array}$ \\
\hline
\end{tabular}

Regression with LSNS Friends at Time 2 as Outcome 


\begin{tabular}{|c|c|c|c|c|c|c|}
\hline $\begin{array}{l}\text { LSNS Friends } \\
\text { at Time } 1\end{array}$ & 0.57 & 0.58 & 0.04 & 15.42 & $<0.001$ & $\begin{array}{l}0.5 \\
0.65\end{array}$ \\
\hline Neuroticism & -0.09 & -0.06 & 0.06 & -1.59 & $>0.05$ & $\begin{array}{l}-0.21, \\
0.02\end{array}$ \\
\hline $\begin{array}{l}\text { SUM OF } \\
\text { INDIRECT }\end{array}$ & 0.8 & 0.53 & 0.12 & 6.95 & $<0.001$ & $\begin{array}{l}0.58 \\
1.03\end{array}$ \\
\hline EFFECTS & & & & & & \\
\hline $\begin{array}{l}\text { INDIRECT } \\
\text { EFFECT - } \\
\text { LSNS }\end{array}$ & 0.32 & 0.23 & 0.05 & 6.38 & $<0.001$ & $\begin{array}{l}0.22 \\
0.4\end{array}$ \\
\hline RELATIVES & & & & & & \\
\hline $\begin{array}{l}\text { INDIRECT } \\
\text { EFFECT - } \\
\text { LSNS }\end{array}$ & 0.25 & 0.2 & 0.05 & 4.84 & $<0.001$ & $\begin{array}{l}0.15 \\
0.35\end{array}$ \\
\hline NEIGHBOURS & & & & & & \\
\hline $\begin{array}{l}\text { INDIRECT } \\
\text { EFFECT - } \\
\text { LSNS }\end{array}$ & 0.28 & 0.21 & 0.05 & 5.84 & $<0.001$ & $\begin{array}{l}0.19 \\
0.37\end{array}$ \\
\hline FRIENDS & & & & & & \\
\hline $\begin{array}{l}\text { TOTAL } \\
\text { EFFECT }\end{array}$ & 0.86 & 0.66 & 0.12 & 7.47 & $<0.001$ & $\begin{array}{l}0.64 \\
1.09\end{array}$ \\
\hline
\end{tabular}

